\title{
Elective correction of intracardiac lesions resulting from penetrating wounds of the heart
}

\author{
S MORGAN, G MATURANA, J URZUA, R FRANCK, AND J DUBERNET \\ From the Department of Cardiovascular Diseases, Catholic University Hospital, Santiago, Chile
}

ABSTRACT Controversy exists regarding the timing and technique of total correction of traumatic intracardiac lesions. Five patients with penetrating wounds of the heart received emergency treatment aimed at securing normal haemodynamics. No attempt was made to identify intracardiac lesions at this stage. Cineangiography two months to seven years later showed aorto-right ventricular fistulae in all patients, associated in two with aortic cusp laceration and in one with an aorto-left atrial fistula. The surgical approach for aorto-right ventricular fistula was through the right ventricle or aorta. Valvar injuries were treated by plastic reconstruction. All patients showed good clinical results when seen four to 11 years later.

Traumatic intracardiac lesions in patients with stable haemodynamics after initial treatment should be operated on electively. The aortic approach is preferable for aorto-right ventricular fistulae. Conservative plastic repair of valvar injuries achieves long-term competence thus avoiding prosthetic replacement.

Continuous progress in the management of chest trauma and better understanding of cardiopulmonary physiology have led to increased survival of patients with penetrating wounds of the heart. This has permitted the diagnosis of more cases of acquired intracardiac shunts. Today's cardiac surgical techniques permit the repair of almost any type of defect produced by such injuries. Nevertheless, controversy still exists regarding the timing and surgical technique required to accomplish this repair.

The purpose of this paper is to propose therapeutic and technical guidelines derived from the treatment and long-term follow-up of five cases of complex intracardiac lesions.

\section{Case reports}

\section{CASE 1}

An 18-year-old boy suffered a $\cdot 22$ calibre gunshot wound at the level of the third left intercostal space. The bullet was recovered from the posterior thoracic wall. The patient remained in a stable condition, and no bleeding into the pericardium or the pleural cavity was detected. A heart murmur was heard over the left sternal border, but the patient was discharged a few days later without further study and he remained lost to follow-up for seven years. He was next seen with subacute bacterial endocarditis and was treated accordingly. Examination showed wide arterial pulses, loud systolic and diastolic murmurs over the left sternal border, and biventricular enlargement. Four months later haemodynamic and angiographic studies showed two abnormal intracardiac communications, one between the aorta and the right ventricle and the other between the aorta and the left atrium (table).

\section{Summary of cardiac catheterisation findings}

\begin{tabular}{llllc}
\hline $\begin{array}{l}\text { Case } \\
\text { No }\end{array}$ & Type of defect & $\begin{array}{l}\text { Right } \\
\text { ventricular } \\
\text { pressure } \\
(\text { mmHg })\end{array}$ & $\begin{array}{l}\text { Mean } \\
\text { pulmonary } \\
\text { arterial } \\
\text { pressure } \\
(\text { mmHg })\end{array}$ & $\begin{array}{l}\text { Estimated } \\
\text { pulmonary/ } \\
\text { systemic } \\
\text { flow ratio } \\
\left(l / \text { min }^{2} \mathbf{m}^{2}\right)\end{array}$ \\
\hline 1 & $\begin{array}{l}\text { Fistula between } \\
\text { AO-RV and AO-LA }\end{array}$ & $37 / 7$ & 24 & $2: 1$ \\
2 & $\begin{array}{l}\text { Fistula between } \\
\text { AO and RV+AR }\end{array}$ & $32 / 8$ & 26 & $1 \cdot 6: 1$ \\
3 & $\begin{array}{l}\text { Fistula between } \\
\text { AO and RV }\end{array}$ & $42 / 7$ & 30 & Not done \\
4 & $\begin{array}{l}\text { Fistula between } \\
\text { AO and RV }\end{array}$ & $30 / 8$ & 22 & $1 \cdot 7: 1$ \\
5 & $\begin{array}{l}\text { Fistula between } \\
\text { AO and RV+AR }\end{array}$ & $40 / 8$ & 32 & $1 \cdot 6: 1$ \\
\hline
\end{tabular}

$A O=$ A orta; $R V=$ Right ventricle; $L A=L$ eft atrium; $A R=$ Aortic regurgitation. 
Surgical repair was performed with normothermic cardiopulmonary bypass. There was a fistula between the aorta above the right coronary cusp and the outflow tract of the right ventricle, and a second one connecting the non-coronary sinus of Valsalva with the left atrium (fig 1). No valvar lesion was present. Both defects were closed from within the aorta with interrupted sutures buttressed by Teflon felt. The patient's postoperative course was uncomplicated. Eleven years later, there is no evidence of residual defect.

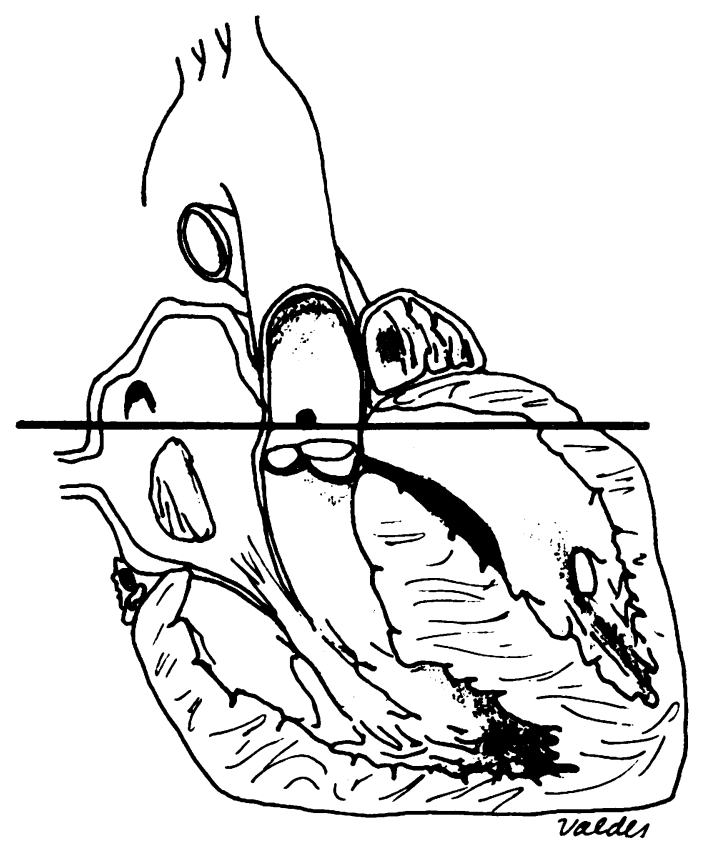

Fig 1 Case 1. A schematic sagittal section of heart illustrates trajectory of bullet, producing lesions of right ventricle, ascending aorta, and left atrium. Projectile emerged from heart and was recovered from posterior thoracic wall. Horizontal line represents trajectory.

\section{CASE 2}

A 21-year-old man was admitted with a stab wound at the level of the left third intercostal space. Blood pressure and pulse were normal. There was no neck vein distension and the heart sounds were audible. A left haemothorax was evacuated by thoracocentesis, and the patient's condition remained stable thereafter. Peripheral signs of aortic regurgitation became evident on the next day. Blood pressure was $130 / 40 \mathrm{mmHg}$ and a loud diastolic murmur was heard over the left sternal border. Two months later cardiac catheterisation (table) and aortography showed grade $3 / 4$ aortic regurgitation and an aorto-right ventricular shunt.

At operation a transverse aortotomy was performed and a fistula was found between the aorta-at the level of the right sinus of Valsalvaand the right ventricular outflow tract. There was a $3 \mathrm{~mm}$ perforation in the right aortic cusp which was sutured with interrupted 5/0 Dacron stitches (fig 2b). The fistula was repaired by direct suture over Teflon pledgets. The patient's postoperative course was uneventful. Eight years' follow-up shows no cardiovascular abnormality.

CASE 3

A 24-year-old man was admitted in profound shock with a stab wound at the level of the third left intercostal space. A left thoracotomy exposed a tense haemopericardium and an actively bleeding laceration of the right ventricular outflow $\vec{\theta}$ tract. This injury was repaired by direct suture and the patient recovered uneventfully. During the postoperative course loud systolic and diastolic murmurs were heard over the left sternal border.

Two months after the initial episode, cardiac catheterisation (table) and aortography disclosed an aorto-right ventricular shunt. At operation, a transverse aortotomy exposed a $4 \mathrm{~mm}$ fistula between the aorta-above the insertion of the right coronary cusp-and the right ventricular outflow tract (fig 2a). The defect was repaired by direct suture over Teflon pledgets. No complications occurred in the postoperative course. Six years' follow-up shows no residual defect.

\section{CASE 4}

A 45 -year-old man received a stab wound at the level of the left third intercostal space. At that 을 time no cardiopulmonary involvement was shown. Three months later he was admitted with a history of progressive dyspnoea. Examination showed $\stackrel{\bar{N}}{.}$ wide peripheral arterial pulses. Blood pressure was $\sigma$ $130 / 60 \mathrm{mmHg}$ and a loud systolic murmur was $\mathrm{N}$ heard over the precordial area.

Haemodynamic and angiographic studies showed an aorto-right ventricular shunt (table).

At operation a $7 \mathrm{~mm}$ fistula was found, con- $\frac{\stackrel{C}{\mathbb{D}}}{\mathscr{D}}$ necting the right ventricular outflow tract and the $\stackrel{\infty}{+}$ aorta, at the level of the right sinus of Valsalva (fig 2a). The defect was repaired through a transverse aortotomy by direct suture over Teflon $\stackrel{\Phi}{\mathscr{Q}}$ pledgets. There was no valvar injury. The post- $\mathbb{Q}$ operative course was uneventful. Four years later, $\overline{0}$ the patient is leading a normal life and has no evidence of residual defect. 

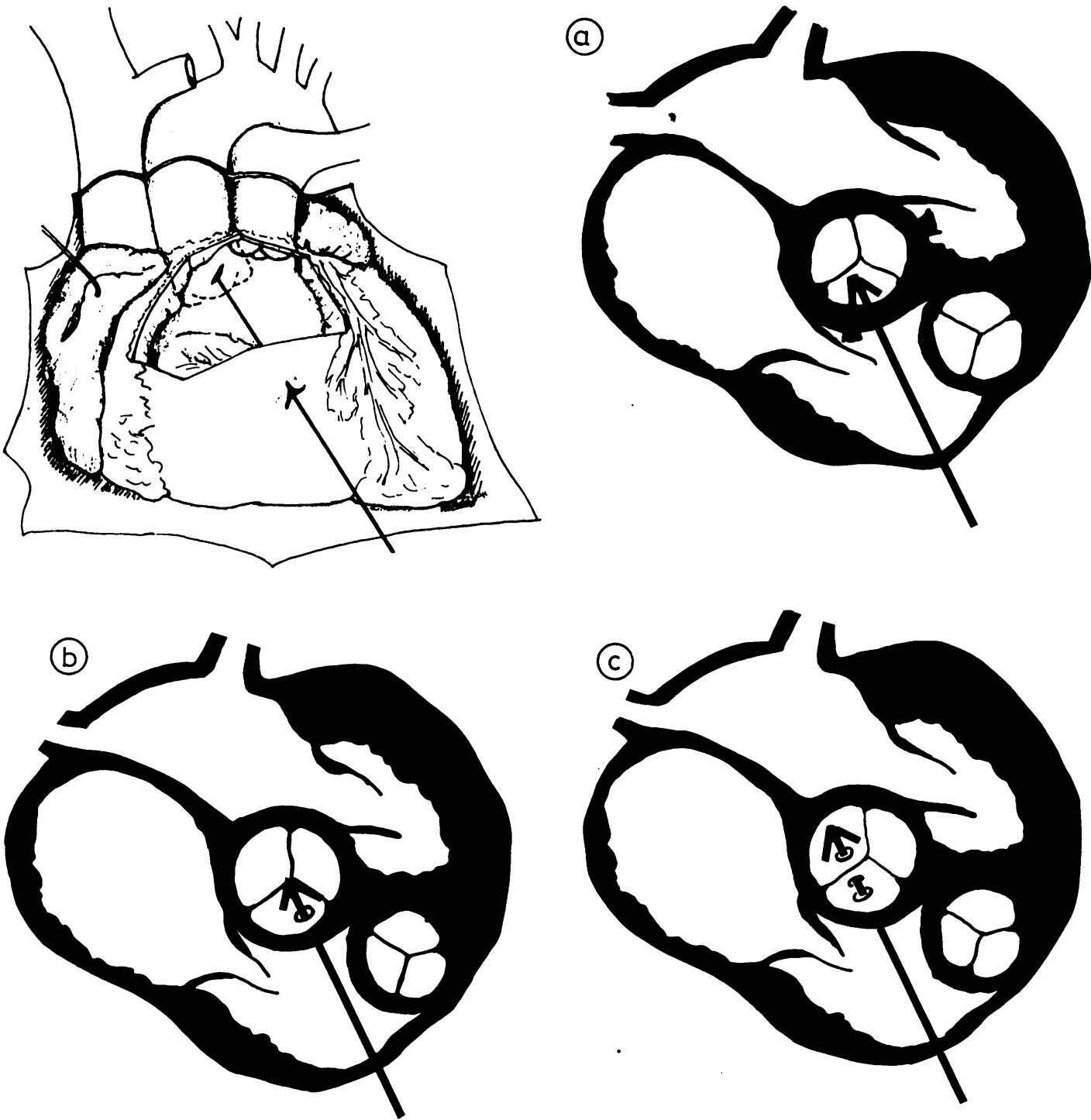

Fig 2 Diagram depicts direction of knife penetration in cases 2-5. As it advances in an anteroposterior and cephalad direction, knife traverses anterior wall of right ventricle, ventricular septum, and aorta. Inserts $(a),(b)$, and $(c)$ show different depths of aortic wound; in (b) there is a tear in the right coronary cusp and in (c) both right and non-coronary cusps are lacerated.

\section{CASE 5}

An 18-year-old boy complaining of progressive shortness of breath was seen in the outpatient department. Three years before, he had suffered a stab wound at the level of the left third intercostal space. No cardiopulmonary involvement was evident immediately after the injury. At the time of admission, examination showed peripheral signs of free aortic regurgitation. The blood press- ure was $110 / 30 \mathrm{mmHg}$ and a grade $5 / 6$ systolic and diastolic murmur was heard over the whole precordial area. Aortography showed a grade 4/4 aortic regurgitation and a connection between the aorta and the right ventricle.

The surgical approach was via a transverse aortotomy which exposed a fistula between the aorta and the right ventricular outflow tract. In addition two $4 \mathrm{~mm}$ perforations were found in 
the right and non-coronary cusps (fig 2c). The fistula was closed by direct suture over Teflon pledgets. Pericardial gussets of adequate size were sutured over each cusp perforation. There were no postoperative complications. Four years later the patient is in functional class I and only a short, soft diastolic murmur is heard over the second right intercostal space.

\section{Discussion}

An increasing number of intracardiac fistulae has been reported in recent years, probably as a result of improved management of patients with penetrating wounds of the heart (Heller et al, 1974; Mattox et al, 1975; Rayner et al, 1977). Nevertheless, the timing of and the techniques for the repair of intracardiac defects resulting from cardiac trauma are still controversial. Some surgeons advocate immediate repair with cardiopulmonary bypass when thoracotomy is necessary, arguing that the haemodynamic derangement caused by such lesions is poorly tolerated (Berger et al, 1969). On the contrary, we as well as others (Beall et al, 1965; Hutchinson et al, 1973) have observed that primary repair of the actively bleeding lesion, together with adequate volume replacement, is all that is needed at this stage. Later, haemodynamic and angiographic studies for identifying the precise anatomy and severity of the injury are mandatory before definitive surgical repair is attempted.

The conventional approach for the closure of fistulae between the aorta and the right ventricle has been a right ventriculotomy (King and Schumacker, 1958; Beall et al, 1965; Summerall et al, 1965). We have found that closure through the aorta is as easily accomplished and has the advantage of permitting simultaneous exploration and repair of valvar injuries when present. Also visualisation of the valve and coronary arteries reduces the chance of damage to these structures during repair.

Lacerations of the aortic valve have been treated either by prosthetic valve replacement (Beall and Shirkey, 1964; Berger et al, 1969) or by direct repair using pericardial gussets when necessary to avoid distortion of the leaflets (Hutchinson et al, 1973). We have observed that conservative repair of previously normal valves has yielded satisfactory long-term results. Of the two patients with aortic valve repair, one has no signs of regurgitation and the other a short diastolic murmur only; both are in functional class I after four and eight years of follow-up, respectively. Another patient previously reported by us (Moran et al, 1977) who had a plastic repair of a ruptured aortic valve is also free of signs of valvar incompetence after three and a half years.

Treatment for patients with penetrating wounds of the heart should depend on their haemodynamic state. Some patients will require only conservative management ranging from clinical observation alone to volume replacement and pericardiocentesis or thoracocentesis. Others, with evidence of active or recurrent bleeding will benefit from emergency thoracotomy and cardiorrhaphy. In both groups of patients residual defects such as those reported here have been well tolerated initially. Case 1 in this series remained asymptomatic for seven years until he developed subacute bacterial endocarditis. Ehrenstein et al (1971) reported the case of a patient with an aorto-right ventricular shunt and aortic regurgitation who survived 17 years. Most patients nevertheless will require surgical treatment for the control of heart failure, especially those with large intracardiac shunts or valvar regurgitation or both (King and Schumacker, 1958; Nowlan et al, 1962; Berger et al, 1969; Treasure et al, 1971; Heller et al, 1974). With careful preoperative studies and the surgical techniques herein described, definitive surgical repair can be achieved with low risk and satisfactory long-term results.

\section{References}

Beall, A, Hamit, H, Cooley, D A, and De Bakey, M E (1965). Surgical management of traumatic intracardiac lesions. Journal of Trauma, 5, 133141.

Beall, A C, and Shirkey, A L (1964). Successful surgical correction of traumatic aortic valve regurgitation. Journal of the American Medical Association, 187, 507-510.

Berger, $\mathbf{R}$ L, Gibson, $H$, Riemer, $R$ W, and Ramaswamy, K (1969). Traumatic aortic regurgitation, ventricular septal defect and fistula of the sinus of Valsalva. New England Journal of Medicine, 281, 887-888.

Ehrenstein, F L, Bahler, R C, Ankeny, J, and Schwartz, H (1971). Untreated (combined) intracardiac and valvular trauma with long asymptomatic survival. American Heart Journal, 81, 685-687.

Heller, R, Rahimtoola, S, Ehsani, A, Johnson, S, Boyd, D, Tatooles, C, Loeb, H, and Rosen, K (1974). Cardiac complications. Results of penetrating chest wounds involving the heart. Archives of Internal Medicine, 134, 491-496.

Hutchinson, J E, Schmidt, D M, Cameron, A, and McCord, C W (1973). The surgical management of intracardiac defects due to penetrating trauma. Journal of Thoracic and Cardiovascular Surgery, 65, 103-107. 
King, H, and Schumacker, H (1958). Surgical repair of a traumatic aorto-right ventricular fistula. Journal of Thoracic Surgery, 35, 734-739.

Mattox, K L, Von Koch, L, Beall, A C, and De Bakey, M E (1975). Logistic and technical considerations in the treatment of the wounded heart. Circulation, 51, suppl I, 210-214.

Morán, S V, Maturana, G, Casanegra, P, and Dubernet, J (1977). Spontaneous rupture of a fenestrated aortic valve: surgical treatment. Journal of Thoracic and Cardiovascular Surgery, 73, 716-718.

Nowlan, J, Steiger, Z, Bicoff, P, Fell, E, and Tobin, R (1962). Traumatic aortic-right ventricular fistula. Journal of the American Medical Association, 182, 159-160.
Rayner, A, Fulton, R, Hess, Ph, and Daicoff, G (1977). Post-traumatic intracardiac shunts. Journal of Thoracic and Cardiovascular Surgery, 73, 728-732.

Summerall, Ch P, Lee, W H, and Boone, J A (1965). Intracardiac shunts after penetrating wounds of the heart. New England Journal of Medicine, 272, 240 242.

Treasure, R, Green, D, Bedyneck, J, and Hopeman, A (1971). Aortocardiac fistula. Journal of Thoracic and Cardiovascular Surgery, 62, 818-821.

Requests for reprints to: $\mathrm{Dr} S$ Moran, Hospital Clinico Universidad Catolica, Cirugia de Torax, Marcoleta 347, Santiago.

\section{International symposium: Clinical importance of surfactant defects}

Hamburg, Germany: 31 October-2 November 1979.

Further details may be obtained from:

Professor Dr P v Wichert, I Medizinische Universitätsklinik, Hamburg Eppendorf, Martinistrasse 52, D 2000 Hamburg 20. 